\title{
Analisis Lanjut Metode Beda Hingga Eksplisit Untuk Menentukan Harga Opsi
}

\author{
Wahyudi $^{1}$ \\ ${ }^{1}$ Universitas Muhammadiyah Ponorogo,wahyudi@umpo.ac.id
}

\begin{abstract}
Explicit finite difference method is used to approximate a partial differential equation that is applied to determine the option pricing. The results of this study note that the calculation of option pricing using explicit finite difference method is negative when partition $N \geq 25$ with a value of -2.21 . Thus, the results of the calculation of option pricing are not convergent and away from the results of analyzing the option pricirng (Black-Scholes) solution. This is because one of the three probabilities $b_{j}=1-\sigma^{2} j^{2} \Delta t$ is negative, namely (-0.12) when $j \geq 12$ with $S \geq 16.25$ (in units). So this explicit finite difference method cannot be used to determine the option pricing.
\end{abstract}

Keywords: Option Pricing, Explicit Finite Difference Method

\begin{abstract}
Abstrak. Metode beda hingga eksplisit digunakan untuk mengaproksimasi suatu persamaan diferensial pasial yang aplikasikan untuk menentukan harga opsi. Hasil penelitian ini diketahui bahwa perhitungan harga opsi dengan menggunakan metode beda hingga eksplisit bernilai negatif pada saat partisi $N \geq 25$ dengan nilai $-2,21$. Dengan demikian, hasil perhitungan harga opsi tidak konvergen dan menjauhi hasil solusi analitik perhitungan harga opsi (Black-Scholes). Hal ini disebabkan karena salah satu ketiga probabilitas yaitu $b_{j}=1-\sigma^{2} j^{2} \Delta t$ bernilai negatif yaitu $(-0.12)$ saat $j \geq 12$ dengan $S \geq 16.25$ (dalam satuan). Sehingga metode beda hingga eksplisit ini tidak dapat digunakan untuk menentukan harga opsi.
\end{abstract}

Kata Kunci: Harga Opsi, Metode Beda Hingga Eksplisit.

\section{Pendahuluan}

Kegunaan opsi dalam perdagangan derivatif (kontrak antar dua pihak) keuangan yaitu melindungi investasi seseorang dengan memperjual belikan opsi (disisi lain jual beli sahamnya). Dengan demikian, perlu adanya ketelitian dalam menentukan nilai opsi tersebut sehingga dapat menyelamatkan investasinya di persaingan harga saham. Menurut Niwiga (2005) kontrak antar dua pihak tersebut adalah pihak memberi hak kepada pihak lain untuk menjual atau membeli aset tertetu pada harga dan periode wajtu tertentu. Menurut Hull (2003) terdapat dua kontrak opsi yaitu opsi call dan opsi put. Opsi call adalah opsi dengan memberikan hak kepada pembeli sutau aset tertentu dengan jumlah tertentu pada harga yang telah ditentukan selama periode tertentu, sedangkan opsi put merupakan opsi dengan memberikan hak kepada pihak lain untuk menjual suatu aset tertentu dengan jumlah tertentu pada harga yang telah ditentukan selama periode tertentu. Berdasarkan waktu eksekusi terdapat dua tipe opsi yaitu opsi Eropa dan opsi Asia. 
Wiklund (2012) menyatakan bahwa untuk opsi Asia belum ada solusi analitiknya, sehingga untuk mendapatkan solusinya perlu adanya metode pendekatan atau aproksimasi, sedangkan opsi Eropa terdapat solusi analitiknya dari model persamaan Black-Scholes berikut

$$
\frac{\partial V}{\partial t}+r S \frac{\partial V}{\partial S}+\frac{1}{2} \sigma^{2} S^{2} \frac{\partial^{2} V}{\partial S^{2}}=r V
$$

dengan $V$ menyatakan harga opsi, $t$ menyatakan waktu berlakunya opsi, $r$ menyatakan tingkat suku bunga, $\sigma$ menyatakan volatilitas harga saham dan $S$ menyatakan harga saham. Menurut (Causon dan Mingham, 2010) metode beda hingga merupakan metode numerik yang digunakan untuk menyelesaikan suatu persamaan diferensial parsial.

Misalkan $V(t, S)$ menyatakan nilai opsi dengan peubah $t$ an $S$, maka persamaan Black-Sholes dapat dinyatakan sebagai berikut

$$
\frac{\partial V(t, S)}{\partial t}+r S \frac{\partial V(t, S)}{\partial S}+\frac{1}{2} \sigma^{2} S^{2} \frac{\partial^{2} V(t, S)}{\partial S^{2}}=r V(t, S)
$$

Untuk mengaproksimasi turunan-turunan persamaan parsial dengan menggunakan ekspansi deret Taylor (Nugroho, 2009). Bentuk umum deret Taylor adalah sebagai berikut (Hernadi, 2015)

$$
V(S)=V\left(S_{0}\right)+\frac{\left(S-S_{0}\right)}{1 !} V^{\prime}\left(S_{0}\right)+\frac{\left(S-S_{0}\right)^{2}}{2 !} V^{\prime \prime}\left(S_{0}\right)+\ldots+\frac{\left(S-S_{0}\right)^{n}}{n !} V^{n}\left(S_{0}\right)
$$

Misal $\left(S-S_{0}\right)=\Delta S$, maka diperoleh

$$
V(x)=V\left(S_{0}\right)+\frac{\Delta S}{1 !} V^{\prime}\left(S_{0}\right)+\frac{\Delta S^{2}}{2 !} V^{\prime \prime}\left(S_{0}\right)+\ldots+\frac{\Delta S^{n}}{n !} V^{m}\left(S_{0}\right)
$$

Berikut aproksimasi turunan pertama dan turunan kedua dengan ekspansi deret Taylor. Persamaan beda maju

$$
\frac{\partial V}{\partial S} \approx \frac{V(t, S+1)-V(t, S)}{\Delta S}
$$

dan persamaan beda mundur

$$
\frac{\partial V}{\partial S} \approx \frac{V(t, S)-V(t, S-\Delta S)}{\Delta S}
$$

Dari hasil pengurangan persamaan beda maju dan persamaan beda mundur diperoleh persamaan beda pusat yaitu

$$
\frac{\partial V}{\partial S} \approx \frac{V(t, S+\Delta S)-V(t, S-\Delta S)}{2 \Delta S}
$$

Untuk aproksimasi turunan kedua dengan menggunakan

$$
V^{\prime \prime}(t, S) \approx \frac{V(t, S+\Delta S)-2 V(t, S)+V(t, S-\Delta S)}{\Delta S^{2}}
$$

Aproksimasi turunan pertama terhadap t, untuk persamaan beda maju yaitu

$$
\frac{\partial V}{\partial t} \approx \frac{V(t+\Delta t, S)-V(t, S)}{\Delta t}
$$

dengan $V(t, S)=V(i, j)$, maka diperoleh

$$
\frac{\partial V}{\partial t} \approx \frac{V(i+1, j)-V(i, j)}{\Delta t}
$$


Persamaan beda mundurnya adalah

$$
\frac{\partial V}{\partial t} \approx \frac{V(t, S)-V(t+\Delta t, S)}{\Delta t}
$$

dengan $V(t, S)=V(i, j)$, maka diperoleh

$$
\frac{\partial V}{\partial t} \approx \frac{V(i, j)-V(i+1, j)}{\Delta t}
$$

Untuk mendiskritisasi model persamaan Black-Scholes dengan metode beda hingga eksplisit dengan memisalkan $V(t, S)=V(i, j)$, diperoleh

$$
\begin{aligned}
& \frac{\partial V}{\partial t} \approx \frac{V_{i+1, j}-V_{i, j}}{\Delta t} \\
& \frac{\partial V}{\partial S} \approx \frac{V_{i+1, j+1}-V_{i+1, j-1}}{2 \Delta S} \\
& \frac{\partial^{2} V}{\partial S^{2}} \approx \frac{V_{i+1, j+1}-2 V_{i+1, j}+V_{i+1, j-1}}{\Delta S^{2}}
\end{aligned}
$$

Kemudian persamaan (13), (14), dan (15) disubstitusikan ke persamaan beda dalam persamaan Black-Sholes, maka diperoleh

$$
V_{i, j}=\frac{1}{1+r \Delta t}\left(a_{j} V_{i+1, j-1}+b_{j} V_{i+1, j}+c_{j} V_{i+1, j+1}\right)
$$

untuk $\mathrm{i}=\mathrm{N}-1, \ldots, 1,0$ dan $\mathrm{j}=1,2, \ldots, \mathrm{M}-1$ dengan

$$
a_{j}=\frac{\sigma^{2} j^{2} \Delta t}{2}-\frac{r j \Delta t}{2}, b_{j}=1-\sigma^{2} j^{2} \Delta t, \text { dan } c_{j}=\frac{\sigma^{2} j^{2} \Delta t}{2}+\frac{r j \Delta t}{2}
$$

Menurut Hull (2003) persamaan (1) merupakan persamaan diferensial parsial yang diaplikasikan untuk perubahan harga saham. Dengan demikian, sebelum menenukan harga saham, terlebih dahulu menentukan harga opsi untuk menyelamatkan investasi yang sudah dilakukan. Dalam penelitian Wahyudi (2014), sebelum metode beda hingga digunakan untuk menentukan harga opsi Asia, terlebih dahulu digunakan untuk menentukan harga opsi Eropa. Karena dalam menentukan harga opsi Eropa sudah terdapat solusi analitiknya, sehingga saat menggunakan metode beda hingga untuk menentukan harga opsi Eropa hasilnya sesuai dengan solusi analitiknya, maka metode beda hingga ini dapat digunakan selanjutnya untuk menentukan harga opsi Asia.

Wahyudi (2014) menggunakan tiga metode beda hingga yaitu metode implisit, eksplisit, dan Crank-Nicholson. Namun pada hanya metode beda hingga eksplisit saja yang tidak dapat diaplikasikan untuk menentukan harga opsi. Dengan demikian, ini menjadi alasan peneliti untuk menganalisis lanjut ketidakvalidan metode beda hingga eksplisit untuk menentukan harga opsi.

\section{Metode Penelitian}

Dalam penelitian ini akan dibahas penyelesaian dari permasalahan tersebut, yaitu dengan metode literatur dari berbagai sumber literatur-literatur yang mendukung, guna mengetahui perkembangan dan perbaikan metode perhitungan harga opsi dengan menggunakan metode beda hingga eksplisit. 


\section{Pembahasan}

Metode beda hingga eksplisit yang digunakan untuk menentukan harga opsi ini konsepnya sama seperti metode trinomial. Sebagaimana Hull (2003) menyatakan bahwa metode beda eksplisit ini ekuivalen dengan metode trinomial yaitu memiliki tiga kemungkinan (probabilitas) masing-masing pada persamaan (17) yang mana nilai $a_{j}, b_{j}, c_{j}$ adalah koefisien dari matriks penentu harga opsi dengan metode beda hingga eksplisit. Probabilitas yang dimaksud di atas adalah

$a_{j}=\frac{\sigma^{2} j^{2} \Delta t}{2}-\frac{r j \Delta t}{2}:$ probabilitas harga opsi dari $j \Delta S$ ke $(j-1) \Delta S$ dengan partisi waktu $\Delta t$

$b_{j}=1-\sigma^{2} j^{2} \Delta t \quad$ : probabilitas harga opsi tetap pada saat $j \Delta S$ ke dengan partisi waktu $\Delta t$

$>c_{j}=\frac{\sigma^{2} j^{2} \Delta t}{2}+\frac{r j \Delta t}{2}:$ probabilitas harga opsi dari $j \Delta S$ ke $(j+1) \Delta S$ dengan partisi waktu $\Delta t$

Ketiga kemungkinan dari metode beda hingga eksplisit dapat dibentuk dalam interpretasi metode trinomial sebagai berikut.

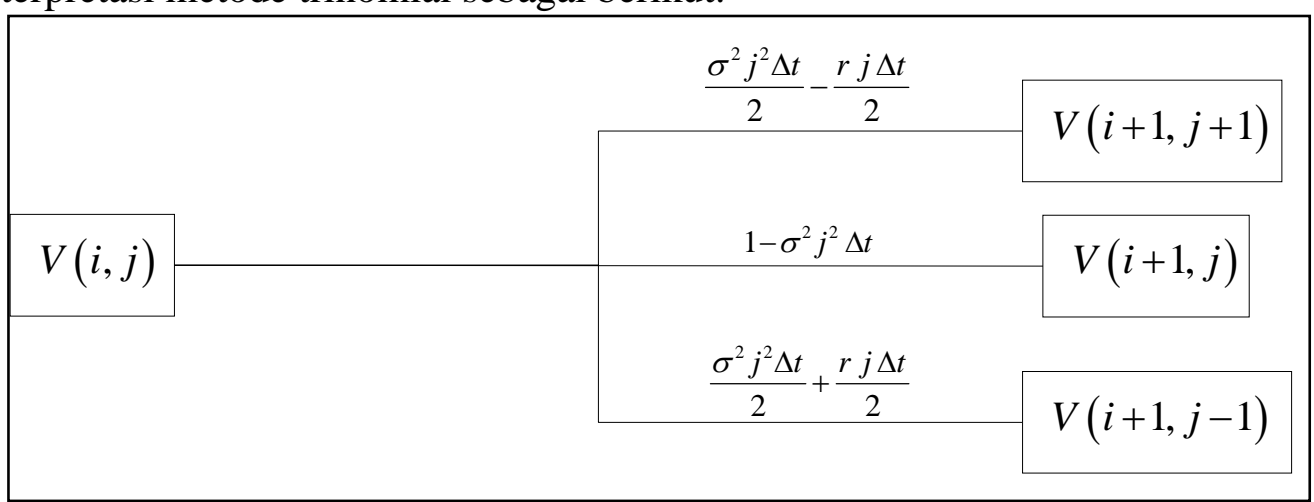

Gambar 1 Metode Beda Hiingga Eksplisit ekuivalen dengan Metode Trinomial

Menurut Hull (2003) metode beda hingga eksplisit merupakan metode yang dapat diaplikasikan untuk menentukan harga opsi dengan ketiga probabilitas $a_{j}=\frac{\sigma^{2} j^{2} \Delta t}{2}-\frac{r j \Delta t}{2}, b_{j}=1-\sigma^{2} j^{2} \Delta t$, dan $c_{j}=\frac{\sigma^{2} j^{2} \Delta t}{2}+\frac{r j \Delta t}{2}$ dengan $a_{j}, b_{j}$, dan $c_{j}$ bernilai positif. Perhitungan harga opsi dengan menggunakan metode beda hingga eksplisit berbantuan MATLAB, hasil perhitungan dengan partisi $N=25$ adalah sebagai berikut.

Tabel 1 Simulasi Perhitungan Harga Saham dan Harga Opsi dengan Metode Beda Hingga Eksplisit

\begin{tabular}{ccc}
\hline Partisi $N$ & Harga Saham (dalam satuan) & Harga Opsi(dalam satuan) \\
\hline 1 & 1.25 & 0 \\
2 & 2.5 & 0 \\
3 & 3.75 & 0.00000384304315 \\
4 & 5.0 & 0.00000122614022 \\
5 & 6.25 & 0.00000084966809 \\
6 & 7.5 & 0.00000054397682 \\
7 & 8.75 & 0.00000031413567
\end{tabular}




\begin{tabular}{ccc}
8 & 10.0 & 0.00000013924646 \\
9 & 11.25 & 0.00000144060867 \\
10 & 12.5 & 0.00000106391114 \\
11 & 13.75 & 0.00000074930331 \\
12 & 15.0 & 0.00000048470366 \\
13 & 16.25 & 0.00000037975674 \\
14 & 17.5 & 0.00000028909633 \\
15 & 18.75 & 0.00000021005946 \\
16 & 20.0 & 0.00000014047302 \\
17 & 21.25 & 0.00000235955034 \\
18 & 22.5 & 0.00000301177920 \\
19 & 23.75 & 0.00000409695495 \\
20 & 25.0 & 0.00000587782443 \\
21 & 26.25 & 0.00000884047306 \\
22 & 27.5 & 0.00001372637291 \\
23 & 28.75 & 0.00002191748496 \\
24 & 30.0 & 0.00003589951710 \\
25 & 31.25 & -0.01541514989301 \\
\hline
\end{tabular}

Berdasarkan Tabel 1 dapat diketahui bahwa harga opsi bernilai negatif mulai dari partisi $N \geq 25$. Dengan demikian, hasil perhitungan harga opsi ini semakin partisi diperbesar semakin menjauhi solusi analitiknya yaitu hasil perhitungan harga opsi. Sehingga metode beda hingga eksplisit ini tidak efektif jika digunakan untuk menentukan harga opsi. Selain itu, dari salah satu ketiga kemungkinan (probabilitas) bernilai nol, yaitu probabilitas harga saham pada saat $j \Delta S$ ke dengan partisi waktu $\Delta t$. Pada perhitungan dengan menggunakan metode beda hingga eksplisit ini, $b_{j}=1-\sigma^{2} j^{2} \Delta t$ bernilai negatif yaitu $(-0.12476606363069)$ saat $j \geq 12$ dengan $S \geq 16.25$ (dalam satuan).

$\begin{array}{rrrr}0.00000000000000 & 0.00000000000000 & 0.00000000000000 & 0.00000000000000 \\ -0.00000000000000 & 0.00000000000000 & 0.00000000000000 & 0.00000000000000 \\ 0.00000000000000 & -0.00000000000000 & 0.00000000000000 & -0.00000000000000 \\ -0.00000000000000 & 0.00000000000000 & -0.00000000000000 & 0.00000000000000 \\ 0.00000000000000 & -0.00000000000000 & 0.00000000000000 & -0.00000000000000 \\ -0.00000000000000 & 0.00000000000000 & -0.00000000000000 & 0.00000000000000 \\ 0.00000000000000 & -0.00000000000000 & 0.00000000000000 & -0.00000000000000 \\ -0.00000000000000 & 0.00000000000000 & -0.00000000000000 & 0.00000000000000 \\ 0.00000000000000 & -0.00000000000000 & 0.00000000000000 & -0.00000000000000 \\ -0.0000000000000 & 0.00000000000000 & -0.00000000000000 & 0.00000000000000 \\ 0.00000000000001 & -0.00000000000000 & 0.00000000000000 & -0.00000000000000 \\ -0.00000000000015 & 0.00000000000001 & -0.00000000000000 & 0.00000000000000 \\ 0.00000000000311 & -0.00000000000025 & 0.00000000000002 & -0.00000000000000 \\ -0.00000000005493 & 0.00000000000451 & -0.00000000000036 & 0.00000000000003 \\ 0.00000000081196 & -0.00000000006735 & 0.00000000000553 & -0.00000000000045 \\ -0.00000001015094 & 0.00000000084947 & -0.00000000007051 & 0.00000000000579 \\ 0.00000010816135 & -0.00000000911740 & 0.00000000076365 & -0.00000000006346 \\ -0.00000098840610 & 0.00000008381120 & -0.00000000707126 & 0.00000000059293 \\ 0.00000778374926 & -0.00000066318760 & 0.00000005628606 & -0.00000000475427 \\ -0.00005300997010 & 0.00000453402157 & -0.00000038665219 & 0.00000003285210 \\ 0.00031290557916 & -0.00002684633809 & 0.00000229817888 & -0.00000019619102 \\ -0.00160235115781 & 0.00013781625697 & -0.00001183374568 & 0.00000101403269 \\ 0.00711488066285 & -0.00061313352482 & 0.00005277408123 & -0.00000453565903 \\ -0.02733296484207 & 0.00235902763471 & -0.00020342914036 & 0.00001752426846 \\ 0.09045477358738 & -0.00781600110149 & 0.00067498110200 & -0.00005824970293 \\ -0.25600371465962 & 0.02214024901573 & -0.00191409526028 & 0.00016540638060 \\ 0.61243966313447 & -0.05300081337495 & 0.00458578699492 & -0.00039667629894 \\ -1.21508540449612 & 0.10520309784793 & -0.00910773989648 & 0.00078839440776 \\ 1.93365060998165 & -0.16747036618348 & 0.01450411685104 & -0.00125613505669 \\ -2.30598175503725 & 0.19975750570943 & -0.01730471897956 & 0.00149914480313 \\ 1.69850962416630 & -0.14715064901674 & 0.01274916604422 & -0.00110467082146\end{array}$

Gambar 2 Sebagian Hasil Perhitungan Harga Opsi

Salah satu ketiga kemungkinan bernilai negatif, mengakibatkan nilai harga opsi dan ketidakkonsistenan harga opsi lain bernilai negatif dan berikut sebagian dari hasil perhitungan harga opsi yang menggunakan metode beda hingga eksplisit yang ditunjukkan pada Gambar 2 di atas. Dengan demikian, salah satu ketiga 
probabilitas bernilai negatif, maka solusi dari hasil perhitungan harga opsi dengan menggunakan metode beda hingga tidak konvergen ke satu titik atau tidak mendekati solusi analitiknya dan metode beda hingga eksplisit ini tidak dapat gunakan untuk menentukan harga opsi. Perhitungan harga opsi dengan menggunakan metode beda hingga eksplisit merupakan ilustrasi perhitungan harga opsi dengan nilai yang ditentukan oleh peneliti. Jika metode ini dapat memberikan nilai yang benar, maka metode ini dapat digunakan untuk menghitung harga opsi yang sesungguhnya.

\section{Kesimpulan}

Berdasarkan hasil pembahasan, dapat diketahui bahwa perhitungan harga opsi dengan menggunakan metode beda hingga eksplisit bernilai negatif pada saat partisi $N \geq 25$ dengan nilai -2,205174218676090. Dengan demikian, hasil perhitungan harga opsi tidak konvergen dan menjauhi hasil solusi analitik perhitungan harga opsi (Black-Scholes). Hal ini disebabkan karena salah satu ketiga probabilitas yaitu $b_{j}=1-\sigma^{2} j^{2} \Delta t$ bernilai negatif yaitu (0.12476606363069 ) saat $j \geq 12$ dengan $S \geq 16.25$ (dalam satuan). Seharusnya ketiga probabilitas dalam ilustasi (simulasi) perhitungan harga saham bernilai positif. Dengan demikian, metode beda hingga eksplisit ini tidak dapat digunakan untuk menentukan harga opsi.

\section{Daftar Pustaka}

[1] Niwiga, D. B., Numerical Methods For The Valuation Of Financial Derivatives, University of Werstern Cape, 2005.

[2] Hull, J. C., Option Future and Other Derivative, Prentice Hall International Inc, 2003.

[3] Wiklund, E., Asian Option Pricing and Volatility, Institute of Technology, 2012.

[4] Causon, D.M. \& Mingham, C.G., Introductory Finite Difference Methods for PDEs, Ventus Publishing ApS, 2010.

[5] Nugroho, D.B., Metode Numerik, Universitas Kristen Satya Wacana, 2009.

[6] Hernadi, J., Analisis Real Elementer, Erlangga, 2015.

[7] Wahyudi, Analisis Metode Beda Hingga Implisit, Eksplisit Dan CrankNicholson Pada Perhitungan Harga Opsi Asia, UIN Malang, 2014. 